\title{
Interannual variability in density, timing and survival of Alaskan red king crab Paralithodes camtschatica larvae
}

\author{
Susan M. Shirley, Thomas C. Shirley \\ Juneau Center for Fisheries and Ocean Sciences, University of Alaska Fairbanks, 11120 Glacier Highway, Juneau, Alaska \\ 99801, USA
}

\begin{abstract}
Larvae of the red king crab Paralithodes camtschatica were sampled with 5 replicate tows of a $1.0 \mathrm{~m}^{2}$ NIO net from March to July, every $2 \mathrm{wk}$ in 1985 and weekly in 1986 through 1988, in Auke Bay, Alaska. Interannual variation existed in time of hatch, length of larval period, larval density. synchrony with the spring phytoplankton bloom, and survival. Hatching occurred earlier, and the period larvae were present was longer, in years with warmer water temperatures. Length of the larval period ranged from $56 \mathrm{~d}$ (1985) to $113 \mathrm{~d}$ (1988). Maximum density of stage 1 zoeae varied from 10 (1988) to 45 per $100 \mathrm{~m}^{3}$ (1987). Larval survival from stage 1 zoea to glaucothoe, estimated by instar analysis, ranged from $0.7{ }^{\circ}$ (1986) to $3 \%(1988$ ), and survival from stage 1 to stage 4 zoeae ranged from $12.6 \%$ in 1986 to $14.9 " \mathrm{\prime}$ in 1987 . Hatching coincided with the spring phytoplankton bloom in 1985 and 1987 , but not in 1986 or 1988 . Survival was not directly related to temporal synchrony of king crab larvae with the spring phytoplankton bloom.
\end{abstract}

\section{INTRODUCTION}

The red king crabs of the eastern Bering Sea region of the North Pacific supported one of the most valuable fisheries on record until a decline in populations resulted in complete closure of the fishery in 1983 after 33 consecutive years of commercial fishing (Blau 1986, Otto 1986). Many investigations since then have attempted to explain the demise. The National Marine Fisheries Service annual trawl surveys and Alaska Department of Fish and Game pre-season pot surveys have not identified strong cohorts recruiting to the population (Blau 1986, Incze et al. 1986).

Survival of meroplanktonic larvae determines recruitment success for many benthic species, and may depend on hydrographic variables, availability of food and predation. The match-mismatch hypothesis proposed for fish larvae suggests that the success or failure of a year-class results from spatial and/or temporal distribution of the larvae in relation to their principal food sources (Cushing 1975, Townsend \& Cammen 1988). An important consideration in larval king crab survival may be the temporal relationship between hatching of crab larvae and the availability of food during the planktonic larval phase.
The larval period of red king crabs consists of 5 stages; 4 zoeal stages and a glaucothoe (Marukawa 1933). Zoeal size and number and specialization of appendages increase with subsequent molts to later zoeal stages (Marukawa 1933, Sato \& Tanaka 1949a). The glaucothoe is similar in appearance to an adult crab except for the retention of the larval abdomen. Glaucothoe are planktonic before settling and molting to the first benthic instar crab. The intermolt period (time between successive larval molts) is influenced by water temperature, and ranges from $9 \mathrm{~d}$ at $8^{\circ} \mathrm{C}$ to $24 \mathrm{~d}$ at $2^{\circ} \mathrm{C}$ (Kurata 1960, Nakanishi 1987, Shirley \& Shirley 1988a). If food is a limiting factor, however, molting will not occur (Paul \& Paul 1980).

Ovigerous king crabs incubate their eggs for ca 11 mo (Marukawa 1933), but water temperature affects the length of incubation in crabs and therefore determines when hatching occurs (Nakanishi 1987. Shirley et al. 1987). Small changes in temperature around $3 \mathrm{C}^{\circ}$ can result in large changes in incubation time (Shirley \& Shirley 1988b). In Auke Bay, Alaska, the phytoplankton bloom is triggered not by water temperature but by light (Ziemann et al. 1987), and therefore is not temporally displaced by a change in temperature, as is hatching of crab eggs. Temperature variations there- 


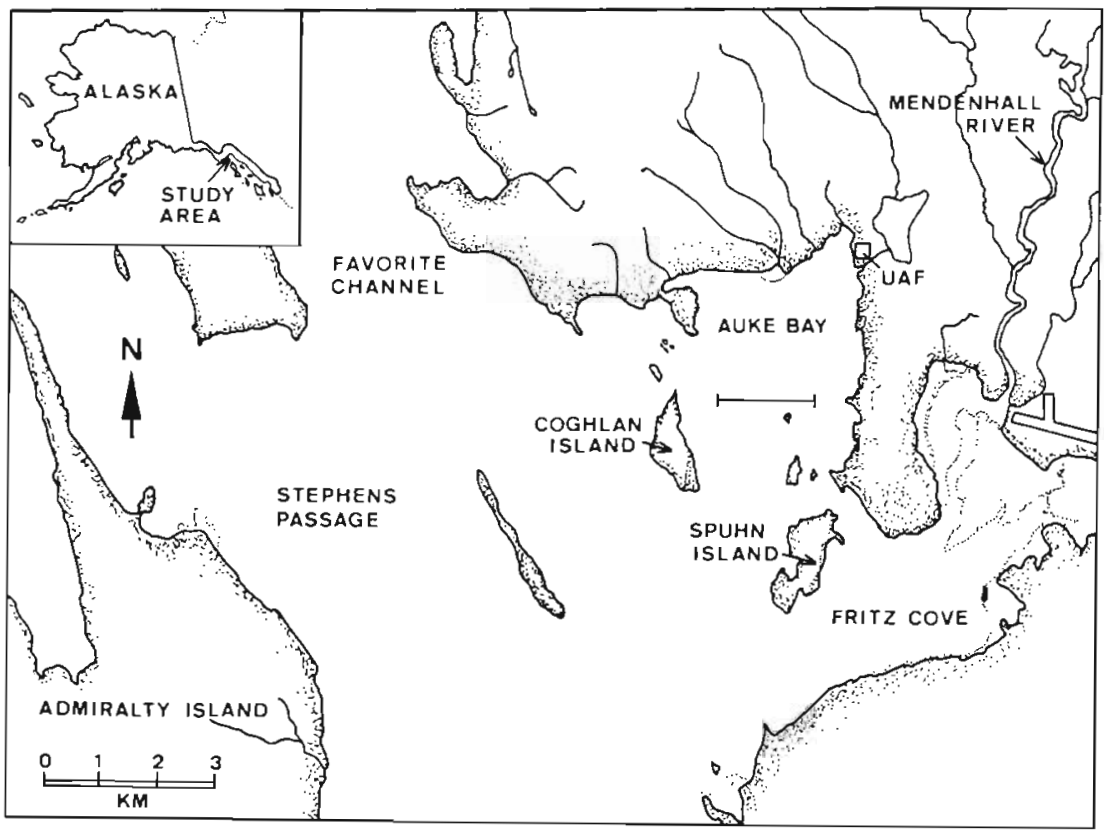

Fig. 1 Location of study area in Auke Bay, Alaska. Horizontal bar in Auke Bay: sampling cruise track; UAF: University of Alaska Fairbanks Juneau Center for Fisheries and Ocean Sciences fore may cause temporal asynchrony in hatching and availability of food, and may be especially critical if initial survival of larvae depends on phytoplankton as a major food source. Successful recruitment through larval metamorphosis and settlement of red king crabs may occur infrequently, producing a population that may be susceptible to depletion if adult stocks are overharvested.

In laboratory cultures, red king crabs feed on a variety of diets, usually mixtures of diatoms and crustacean nauplii (Sato \& Tanaka 1949b, Kurata 1959, 1960, Nakanishi \& Naryu 1981, Paul \& Coyle 1986). Diatoms have been observed in the digestive tracts of first stage king crab zoeae collected from the field (Marukawa 1933 pers. obs.). Newly hatched zoeae are thought to be primarily herbivorous with carnivory increasing in the later zoeal stages.

The spring phytoplankton bloom in Auke Bay consists of a pulse bloom and is primarily composed of the centric diatoms Thalassiosira aestivalis, Skeletonema costatum and Chaetoceros spp. (Sato 1986, Laws et al. 1988). In subarctic ecosystems, a significant percentage of the primary production for the year occurs during the initial spring bloom (Allen 1971, Goering et al. 1973a, b), although smaller blooms may subsequently occur.

Interannual variability in the relationship between the spring phytoplankton bloom and recruitment of commercially important fish and shellfish is the focus of a $5 \mathrm{yr}$ research program of the University of Alaska Fairbanks and the Oceanic Institute (Hawaii) entitled the Association of Primary Production and Recruitment in Subarctic Ecosystems (APPRISE). The objective of this study, as part of APPRISE, was to address the hypothesis that interannual variablility of larval king crab survival and recuritment is related to the timing, duration, magnitude and/or species composition of the spring phytoplankton bloom, and/or physical factors in Auke Bay.

\section{MATERIALS AND METHODS}

All sampling was conducted in Auke Bay, Alaska, ca $20 \mathrm{~km}$ north of Juneau $\left(58^{\circ} 22^{\prime} \mathrm{N}, 134^{\circ} 40^{\prime} \mathrm{W}\right)$ (Fig. 1). Auke Bay is a partially enclosed embayment with an area of about $10 \mathrm{~km}^{2}$ in a system of fjords connected with the Pacific Ocean. Greater than $50 \%$ of the bay is between 40 and $60 \mathrm{~m}$ depth and has a muddy substrate. Semidiurnal tides occur with amplitudes of 3 to $7 \mathrm{~m}$. The bay supports a population of red king crabs that are exploited only by a local sport fishery.

Plankton samples were collected at a single station from March through September, 1985 to 1988, with a $1.0 \mathrm{~m}^{2}$ Tucker trawl equipped with $0.505 \mathrm{~mm}$ aperture mesh. The net was deployed in a double oblique trajectory to a depth of $35 \mathrm{~m}$ and the volume of water filtered was measured with a General Oceanics digital flowmeter. Five replicate samples were collected on each sampling date and fixed in $5 \%$ formalin. Samples were collected weekly in 1986 through 1988, but every 2 wk in 1985. All samples were collected between 08:00 and 12:00 h.

The larvae and glaucothoe of red king crabs were enumerated, by stage, from the plankton samples using the criteria of Marukawa (1933) and Sato \& Tanaka (1949a). Densities were calculated and are reported as larvae per $100 \mathrm{~m}^{3}$ of water filtered. Samples were 
analyzed chronologically until king crab larvae were no longer present in the plankton for 2 consecutive sample periods.

Estimates of in situ mortality of king crab larvae were made using instar analysis (Rigler \& Cooley 1974, Hewitt et al. 1985, Krebs 1985). A life table was constructed using the sum of means for each larval stage and calculating the mortality between stages using the equation:

$$
q_{x}=d_{x} / n_{x}
$$

where $q=$ rate of mortality; $x=$ larval stage $n=$ total number of stage $x$ larvae observed in the plankton samples; $\mathrm{d}=$ number of larvae that die from stage $x$ to $x+1\left(n_{x}-n_{x}+1\right)$ (Krebs 1985).

Hydrographic data, chlorophyll concentrations (mg $\mathrm{m}^{-2}$ ) and phytoplankton species composition data in Auke Bay were collected between 08:30 and 11:00 h twice weekly over the larval period by the Oceanic Institute (Sato 1986, Ziemann 1986, Ziemann et al. 1987. Ziemann et al. 1988). Temperature data is reported as the mean of temperatures at 10,20,30 and $40 \mathrm{~m}$ depths.

\section{RESULTS}

King crab larvae were present in the plankton for $56 \pm 13 \mathrm{~d}$ ( \pm sampling interval), $104 \pm 6 \mathrm{~d}, 85 \pm 6 \mathrm{~d}$, and $113 \pm 6 \mathrm{~d}$ in 1985, 1986, 1987 and 1988, respectively (Fig. 2). Stage 1 zoeae appeared in the water
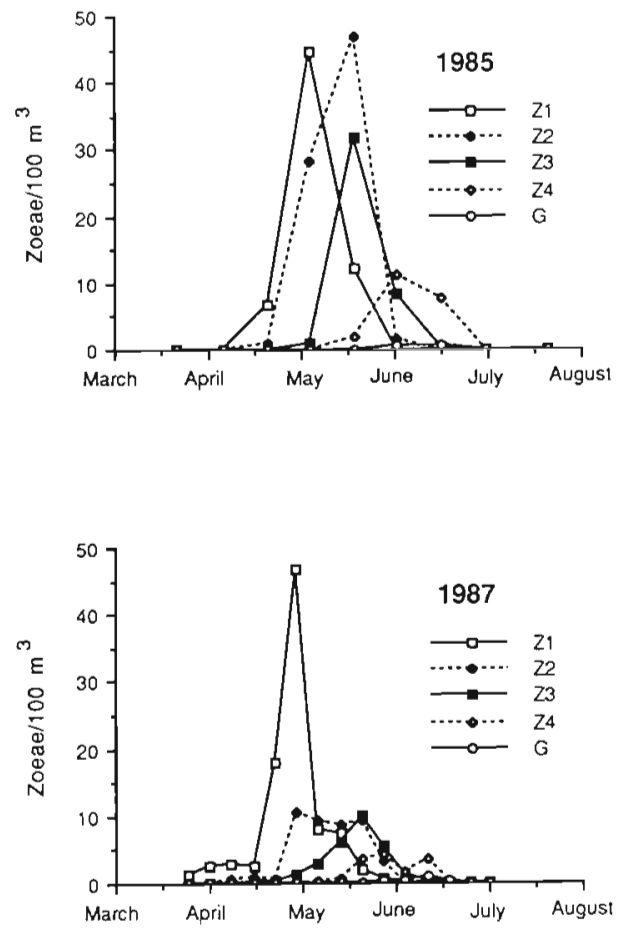

Fig. 3. Paralithodes camtschatica. Mean densities of zoeal stages 1 through 4 (Z1 to Z.4) and glaucothoe (G) of red king crabs in 5 replicate plankton samples collected in Auke Bay, from 1985 to 1988

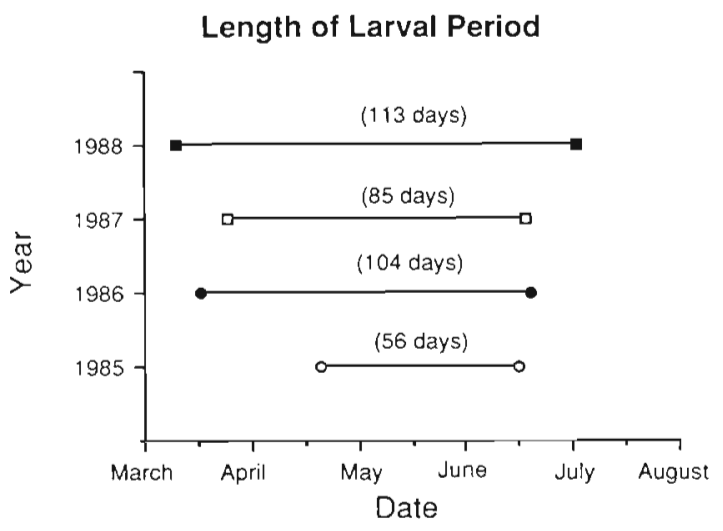

Fig. 2. Paralithodes camtschatica. Length of time red king crab larvae were present in plankton samples collected from Auke Bay, in 1985-1988

column in Auke Bay on 19 April in 1985, 19 March in 1986, 24 March in 1987 and 8 March in 1988. The dates of first occurrence for 1987 and 1988 were calculated by subtracting the length of the intermolt period, $14 \mathrm{~d}$, from the date of first occurrence of stage 2 zoeae to accommodate hatching that began prior to our field sampling (Rigler \& Cooley 1974).

A prominent peak of hatching of king crab eggs is evident from the changes in the density of stage 1 zoeae for all years (Fig. 3, Table 1). In 1986, a small increase in density followed by a decrease was evident on 25 April before the maximum density occurred. In 1988 , the 3 maxima in density of stage 2 zoeae suggest

Table 1. Paralithodes camtschatica. Mean larval density ( \pm SE), by sampling date and larval stage, and number of replicate samples $(n)$ collected on each date from 1985 to 1988

\begin{tabular}{|c|c|c|c|c|c|c|c|}
\hline \multirow[t]{2}{*}{ Year } & \multirow[t]{2}{*}{ Date } & \multirow[t]{2}{*}{$n$} & \multicolumn{5}{|c|}{ Larval density (no. $100 \mathrm{~m}^{-3}$ ) } \\
\hline & & & Zoea 1 & Zoea 2 & Zoea 3 & Zoea 4 & Glaucothoe \\
\hline \multirow[t]{9}{*}{1985} & 21 May & 3 & $0.0 \pm 0.0$ & $0.0 \pm 0.0$ & $0.0 \pm 0.0$ & $0.0 \pm 0.0$ & $0.0 \pm 0.0$ \\
\hline & $5 \mathrm{Apr}$ & 4 & $0.0 \pm 0.0$ & $0.0 \pm 0.0$ & $0.0 \pm 0.0$ & $0.0 \pm 0.0$ & $0.0 \pm 0.0$ \\
\hline & $19 \mathrm{Apr}$ & 4 & $6.9 \pm 0.8$ & $1.1 \pm 0.2$ & $0.0 \pm 0.0$ & $0.0 \pm 0.0$ & $0.0 \pm 0.0$ \\
\hline & 3 May & 3 & $44.5 \pm 1.8$ & $28.3 \pm 3.2$ & $0.8 \pm 0.3$ & $0.0 \pm 0.0$ & $0.0 \pm 0.0$ \\
\hline & 17 May & 3 & $12.2 \pm 0.5$ & $46.9 \pm 3.2$ & $31.7 \pm 2.7$ & $1.9 \pm 0.8$ & $0.0 \pm 0.0$ \\
\hline & 31 May & 4 & $0.0 \pm 0.0$ & $1.5 \pm 0.7$ & $8.4 \pm 1.5$ & $11.2 \pm 2.0$ & $0.6 \pm 0.2$ \\
\hline & 14 Jun & 3 & $0.0 \pm 0.0$ & $0.0 \pm 0.0$ & $0.4 \pm 0.3$ & $7.7 \pm 1.0$ & $0.7 \pm 0.3$ \\
\hline & 28 Jun & 3 & $0.0 \pm 0.0$ & $0.0 \pm 0.0$ & $0.0 \pm 0.0$ & $0.0 \pm 0.0$ & $0.0 \pm 0.0$ \\
\hline & $18 \mathrm{Jul}$ & 4 & $0.0 \pm 0.0$ & $0.0 \pm 0.0$ & $0.0 \pm 0.0$ & $0.0 \pm 0.0$ & $0.0 \pm 0.0$ \\
\hline \multirow[t]{15}{*}{1986} & $19 \mathrm{Mar}$ & 4 & $0.0 \pm 0.4$ & $0.0 \pm 0.0$ & $0.0 \pm 0.0$ & $0.0 \pm 0.0$ & $0.0 \pm 0.0$ \\
\hline & $1 \mathrm{Apr}$ & 5 & $0.4 \pm 0.4$ & $0.0 \pm 0.0$ & $0.0 \pm 0.0$ & $0.0 \pm 0.0$ & $0.0 \pm 0.0$ \\
\hline & $22 \mathrm{Apr}$ & 5 & $6.0 \pm 1.3$ & $0.4 \pm 0.2$ & $0.0 \pm 0.0$ & $0.0 \pm 0.0$ & $0.0 \pm 0.0$ \\
\hline & $28 \mathrm{Apr}$ & 5 & $15.0 \pm 2.2$ & $1.9 \pm 0.4$ & $0.1 \pm 0.1$ & $0.0 \pm 0.0$ & $0.0 \pm 0.0$ \\
\hline & 5 May & 5 & $13.3 \pm 1.2$ & $3.5 \pm 0.4$ & $0.2 \pm 0.2$ & $0.0 \pm 0.0$ & $0.0 \pm 0.0$ \\
\hline & 12 May & 5 & $12.4 \pm 1.9$ & $4.8 \pm 0.5$ & $0.3 \pm 0.1$ & $0.0 \pm 0.0$ & $0.0 \pm 0.0$ \\
\hline & $19 \mathrm{May}$ & 5 & $29.6 \pm 1.6$ & $21.5 \pm 1.7$ & $2.4 \pm 0.5$ & $0.1 \pm 0.1$ & $0.0 \pm 0.0$ \\
\hline & 26 May & 5 & $6.9 \pm 0.7$ & $27.1 \pm 2.8$ & $11.2 \pm 1.8$ & $0.5 \pm 0.2$ & $0.0 \pm 0.0$ \\
\hline & 2 Jun & 5 & $0.4 \pm 0.1$ & $4.9 \pm 0.8$ & $5.0 \pm 0.4$ & $1.2 \pm 0.2$ & $0.0 \pm 0.0$ \\
\hline & 9 Jun & 5 & $0.0 \pm 0.0$ & $0.7 \pm 0.2$ & $2.0 \pm 0.6$ & $1.8 \pm 0.4$ & $0.0 \pm 0.0$ \\
\hline & $16 \mathrm{Jun}$ & 4 & $0.0 \pm 0.0$ & $0.1 \pm 0.1$ & $1.0 \pm 0.3$ & $5.1 \pm 0.8$ & $0.0 \pm 0.0$ \\
\hline & $23 \mathrm{Jun}$ & 5 & $0.0 \pm 0.0$ & $0.0 \pm 0.0$ & $0.1 \pm 0.1$ & $1.9 \pm 0.1$ & $0.5 \pm 0.2$ \\
\hline & $30 \mathrm{Jun}$ & 5 & $0.0 \pm 0.0$ & $0.0 \pm 0.0$ & $0.0 \pm 0.0$ & $0.1 \pm 0.1$ & $0.1 \pm 0.1$ \\
\hline & $8 \mathrm{Jul}$ & 5 & $0.0 \pm 0.0$ & $0.0 \pm 0.0$ & $0.0 \pm 0.0$ & $0.0 \pm 0.0$ & $0.0 \pm 0.0$ \\
\hline & $15 \mathrm{Jul}$ & 5 & $0.0 \pm 0.0$ & $0.0 \pm 0.0$ & $0.0 \pm 0.0$ & $0.0 \pm 0.0$ & $0.0 \pm 0.0$ \\
\hline \multirow[t]{15}{*}{1987} & $24 \mathrm{Mar}$ & 5 & $1.1 \pm 0.3$ & $0.0 \pm 0.0$ & $0.0 \pm 0.0$ & $0.0 \pm 0.0$ & $0.0 \pm 0.0$ \\
\hline & $31 \mathrm{Mar}$ & 5 & $2.7 \pm 0.7$ & $0.0 \pm 0.0$ & $0.0 \pm 0.0$ & $0.0 \pm 0.0$ & $0.0 \pm 0.0$ \\
\hline & 7 Apr & 5 & $2.8 \pm 0.3$ & $0.6 \pm 0.2$ & $0.0 \pm 0.0$ & $0.0 \pm 0.0$ & $0.0 \pm 0.0$ \\
\hline & $14 \mathrm{Apr}$ & 5 & $2.6 \pm 0.6$ & $1.0 \pm 0.2$ & $0.2 \pm 0.1$ & $0.0 \pm 0.0$ & $0.0 \pm 0.0$ \\
\hline & $21 \mathrm{Apr}$ & 5 & $17.8 \pm 1.0$ & $0.7 \pm 0.3$ & $0.2 \pm 0.1$ & $0.0 \pm 0.0$ & $0.0 \pm 0.0$ \\
\hline & $28 \mathrm{Apr}$ & 5 & $46.9 \pm 1.7$ & $10.7 \pm 0.7$ & $1.4 \pm 0.4$ & $0.2 \pm 0.1$ & $0.0 \pm 0.0$ \\
\hline & 5 May & 5 & $8.0 \pm 0.6$ & $9.4 \pm 0.5$ & $3.0 \pm 0.5$ & $0.2 \pm 0.1$ & $0.0 \pm 0.0$ \\
\hline & 12 May & 5 & $7.3 \pm 0.6$ & $8.6 \pm 1.1$ & $6.0 \pm 0.6$ & $0.6 \pm 0.3$ & $0.0 \pm 0.0$ \\
\hline & 19 May & 5 & $2.0 \pm 0.3$ & $9.3 \pm 1.7$ & $10.0 \pm 1.1$ & $3.5 \pm 0.4$ & $0.0 \pm 0.0$ \\
\hline & $26 \mathrm{May}$ & 5 & $0.5 \pm 0.1$ & $3.3 \pm 0.5$ & $5.3 \pm 0.6$ & $4.1 \pm 0.7$ & $0.2 \pm 0.1$ \\
\hline & 2 Jun & 5 & $0.0 \pm 0.0$ & $0.1 \pm 0.1$ & $1.2 \pm 0.4$ & $1.5 \pm 0.4$ & $0.3 \pm 0.2$ \\
\hline & 9 Jun & 5 & $0.0 \pm 0.0$ & $0.0 \pm 0.0$ & $0.3 \pm 0.2$ & $3.4 \pm 0.2$ & $1.0 \pm 0.1$ \\
\hline & 16 Jun & 4 & $0.0 \pm 0.0$ & $0.0 \pm 0.0$ & $0.0 \pm 0.0$ & $0.2 \pm 0.1$ & $0.2 \pm 0.1$ \\
\hline & 23 Jun & 5 & $0.0 \pm 0.0$ & $0.0 \pm 0.0$ & $0.0 \pm 0.0$ & $0.0 \pm 0.0$ & $0.0 \pm 0.0$ \\
\hline & $29 \mathrm{Jun}$ & 5 & $0.0 \pm 0.0$ & $0.0 \pm 0.0$ & $0.0 \pm 0.0$ & $0.0 \pm 0.0$ & $0.0 \pm 0.0$ \\
\hline \multirow[t]{14}{*}{1988} & $22 \mathrm{Mar}$ & 5 & $2.2 \pm 0.7$ & $0.2 \pm 0.1$ & $0.0 \pm 0.0$ & $0.0 \pm 0.0$ & $0.0 \pm 0.0$ \\
\hline & $29 \mathrm{Mar}$ & 5 & $3.1 \pm 0.4$ & $0.4 \pm 0.1$ & $0.0 \pm 0.0$ & $0.0 \pm 0.0$ & $0.0 \pm 0.0$ \\
\hline & $5 \mathrm{Apr}$ & 5 & $9.0 \pm 0.7$ & $2.7 \pm 0.4$ & $0.4 \pm 0.1$ & $0.0 \pm 0.0$ & $0.0 \pm 0.0$ \\
\hline & $12 \mathrm{Apr}$ & 5 & $4.2 \pm 0.7$ & $1.2 \pm 0.2$ & $0.1 \pm 0.1$ & $0.0 \pm 0.0$ & $0.0 \pm 0.0$ \\
\hline & $19 \mathrm{Apr}$ & 5 & $8.7 \pm 1.2$ & $4.5 \pm 0.4$ & $0.4 \pm 0.2$ & $0.1 \pm 0.1$ & $0.0 \pm 0.0$ \\
\hline & $26 \mathrm{Apr}$ & 5 & $10.0 \pm 0.5$ & $6.2 \pm 0.5$ & $0.6 \pm 0.2$ & $0.0 \pm 0.0$ & $0.0 \pm 0.0$ \\
\hline & 3 May & 5 & $6.5 \pm 0.7$ & $1.5 \pm 0.3$ & $0.1 \pm 0.1$ & $0.0 \pm 0.0$ & $0.0 \pm 0.0$ \\
\hline & 10 May & 5 & $0.6 \pm 0.2$ & $2.3 \pm 0.6$ & $0.7 \pm 0.3$ & $0.2 \pm 0.1$ & $0.1 \pm 0.1$ \\
\hline & 17 May & 5 & $1.1 \pm 0.3$ & $3.4 \pm 0.7$ & $2.2 \pm 0.3$ & $0.4 \pm 0.2$ & $0.2 \pm 0.2$ \\
\hline & 24 May & 5 & $0.0 \pm 0.0$ & $0.6 \pm 0.2$ & $2.3 \pm 0.5$ & $3.0 \pm 0.5$ & $0.0 \pm 0.0$ \\
\hline & 31 May & 5 & $0.0 \pm 0.0$ & $0.0 \pm 0.0$ & $0.4 \pm 0.1$ & $1.3 \pm 0.2$ & $0.1 \pm 0.1$ \\
\hline & 7 Jun & 5 & $0.0 \pm 0.0$ & $0.0 \pm 0.0$ & $0.1 \pm 0.1$ & $0.8 \pm 0.2$ & $1.0 \pm 0.2$ \\
\hline & 14 Jun & 5 & $0.0 \pm 0.0$ & $0.0 \pm 0.0$ & $0.0 \pm 0.0$ & $0.1 \pm 0.1$ & $0.0 \pm 0.0$ \\
\hline & 21 Jun & 5 & $0.0 \pm 0.0$ & $0.0 \pm 0.0$ & $0.0 \pm 0.0$ & $0.0 \pm 0.0$ & $0.1 \pm 0.1$ \\
\hline
\end{tabular}


that an earlier maximum in stage 1 zoeal density occurred prior to our sampling. The initial stage 1 cohort can be followed through successive larval stages in all years (Fig. 3). The maximum mean densities for stage 1 zoeae were $44.5 \pm 1.8,29.6 \pm 1.7,46.9 \pm 1.7$ and $10.0 \pm 0.5100 \mathrm{~m}^{-3}$ (mean $\pm \mathrm{SE}$ ), for 1985, 1986, 1987 and 1988, respectively (Fig. 4, Table 1). The 1985 maximum density for stage 2 zoeae exceeded that of stage 1 zoeae and infers that stage 1 zoeae reached maximum density between 3 and 17 May and was missed during the $14 \mathrm{~d}$ sampling interval.

Water temperatures varied over the 4 yr study period with the warmest temperatures in 1988 and the coldest temperatures in 1986 (Fig. 5).

The phytoplankton community of Auke Bay is comprised of about 100 species, but less than $10 \%$ are numerically important. The 3 most common genera are Chaetoceros, Thalassiosira and Skeletonema, with Chaetoceros more abundant in secondary blooms (Sato 1986). During March and early April, phytoplankton concentrations at pre-bloom levels are less than $100 \mathrm{mg}$ chl $\mathrm{m}^{-2}$. A rapid increase in phytoplankton biomass follows with the maximum chlorophyll levels occurring during the last week of April or first week of May (Fig. 6).

Maximum chlorophyll levels were measured on 25 April 1985, 5 May 1986, 4 May 1987 and 29 April 1988,

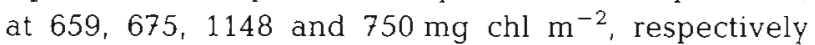
(Sato 1986, Ziemann et al. 1987, 1988, Ziemann pers. comm.; Fig. 6). The spring blooms were generally simi-
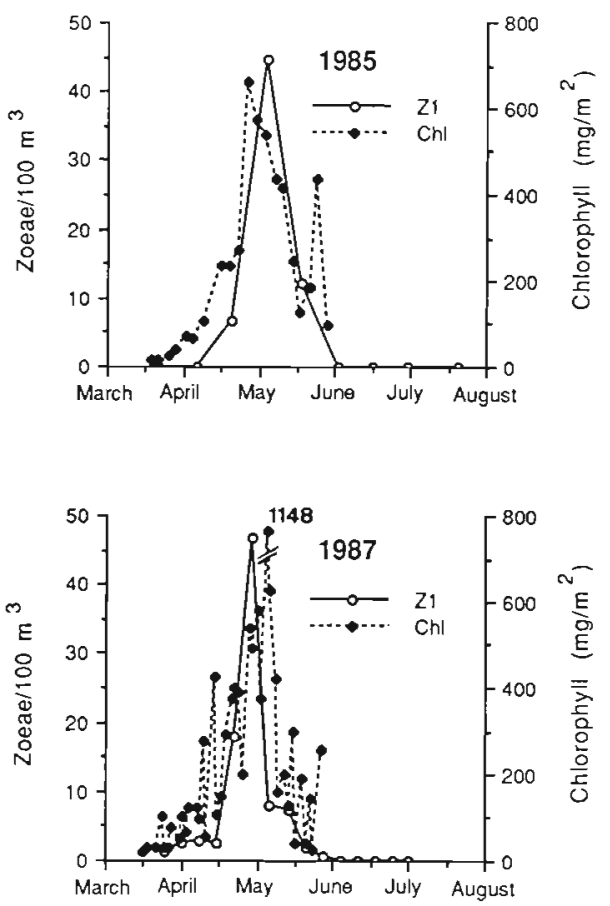

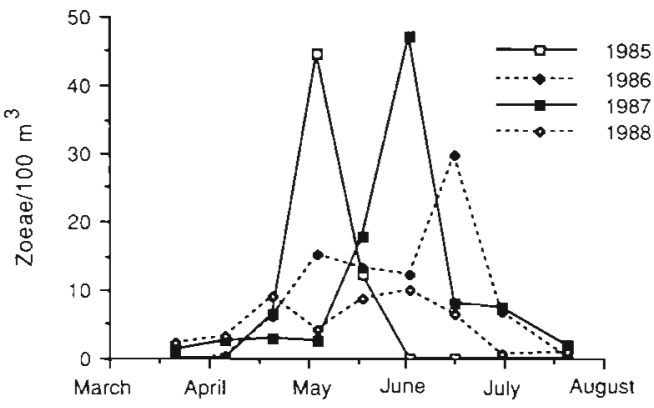

Fig. 4. Paralithodes camtschatica. Comparison of mean densities of stage 1 zoeae of red king crabs from 5 replicate plankton samples collected in Auke Bay, 1985-1988

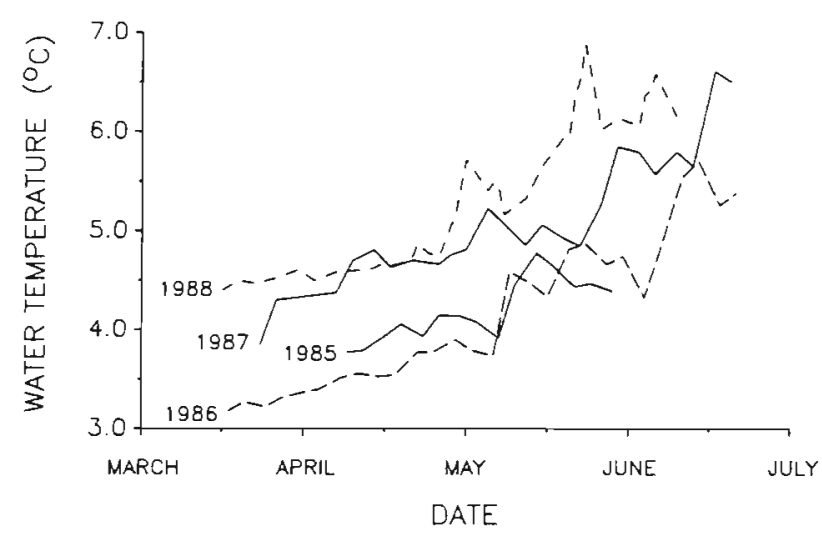

Fig. 5. Mean water temperature in Auke Bay, at depths from 10 to $40 \mathrm{~m}$, during the planktonic larval period of red king crabs, 1985 to 1988
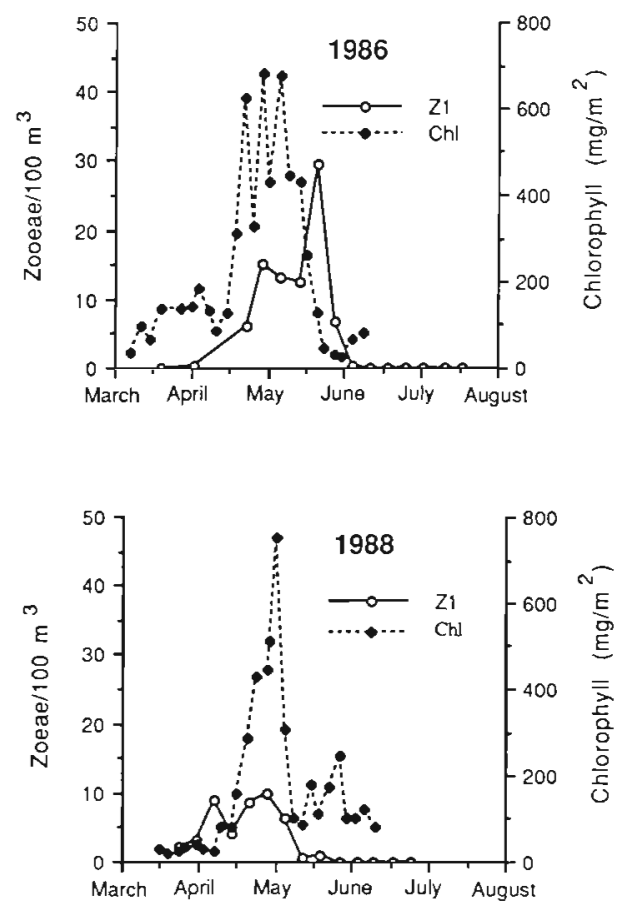

Fig. 6. Paralithodes camtschatica. Temporal relationships of mean densities of stage 1 zoeae of red king crabs to chlorophyll concentrations $(\mathrm{Chl}$, integrated over $35 \mathrm{~m}$ ) during the spring phytoplankton bloom in Auke Bay, 1985 to 1988 . Maximum chlorophyll level in 1987 was $1148 \mathrm{mg} \mathrm{chl} \mathrm{m}^{-2}$ 
Table 2. Paralithodes camtschatica. Estimated mortality and survival of king crab larvae between successive zoeal stages ( 1 through 4 ) and glaucothoe $(G)$

\begin{tabular}{|c|c|c|c|c|c|}
\hline Stage & 1985 & 1986 & 1987 & 1988 & Mean $\pm \mathrm{SE}$ \\
\hline \multicolumn{6}{|c|}{ Percent mortality } \\
\hline 1 to 2 & - & 22.9 & 52.4 & 49.5 & $41.6 \pm 7.7$ \\
\hline 2 to 3 & 46.9 & 65.5 & 36.9 & 68.6 & $54.5 \pm 6.6$ \\
\hline 3 to 4 & 49.9 & 52.6 & 50.3 & 19.5 & $43.1 \pm 6.8$ \\
\hline 4 to $G$ & 98.0 & 99.3 & 98.2 & 97.0 & $98.2 \pm 0.4$ \\
\hline \multicolumn{6}{|c|}{ Percent survival } \\
\hline 1 to $G$ & 2.0 & 0.7 & 1.8 & 3.0 & \\
\hline 1 to 4 & - & 12.6 & 14.9 & 12.8 & \\
\hline
\end{tabular}

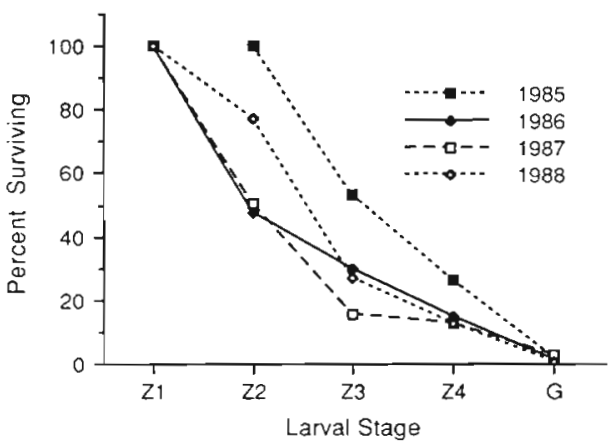

Fig. 7. Paralithodes camtschatica. Estimated percentages of red king crab larvae surviving through the zoeal stages ( $\mathrm{Z} 1$ through Z4) to glaucothoe (G) in Auke Bay, 1985 to 1988

lar in species composition except for the 1988 bloom, which was almost a pure culture of Thalassiosira (Ziemann pers. comm.).

Mortality estimates of king crab larvae varied over the $4 \mathrm{yr}$ period (Table 2). Mortality between zoeal stages 1 and 2 was lowest in 1986, $23 \%$, and highest in 1988, $50 \%$. From zoeal stages 2 to 3, mortality ranged between $37 \%$ in 1987 to $70 \%$ in 1988. Mortality between stages 3 and 4 was lowest in 1988, 20\%, and highest in 1986, $53 \%$. The greatest mortality occurred between zoeal stage 4 and glaucothoe and varied little between years, 97 to $99 \%$. Mortality rates were similar between zoeal stages 1 through 4 , but doubled from stage 4 to glaucothoe. Survival of king crab larvae to the glaucothoe stage varied from 0.7 to $3 \%$ of the total number of stage 1 zoeae (Fig. 7, Table 2). However, settling of glaucothoe could cause estimates of mortality between stage 4 zoeae and glaucothoe to be artificially high. Estimated mortality from stage 1 to stage 4 zoeae may be a more accurate index of larval survival. The estimated survival of king crab larvae from zoeal stages 1 to 4 varied from 12.6 to $14.9 \%$ (Table 2). Survival from stages 1 to 4 was not calculated from 1985 data because the mortality estmate for stage 1 zoeae was missing.

In 1985 and 1987 the hatching of larval king crabs coincided with the spring phytoplankton bloom in Auke Bay (Fig. 6). In 1986, the maximum density of stage 1 zoeae occurred after the bloom, although an earlier, smaller peak in density was coincident with the maximum chlorophyll concentration. In 1988, most of the larvae were released prior to the bloom.

\section{DISCUSSION}

Interannual variability was evident in many aspects of the larval life history of red king crabs in Auke Bay, Alaska, including time of hatching, larval density, length of larval period and survival.

Densities of king crab larvae over the $4 \mathrm{yr}$ period were comparable to all but the highest densities of king crab larvae measured in the Bering Sea from 1969 to 1983 (Haynes 1974, McMurray et al. 1984). In 1987, king crab larval denstities were similar to those obtained from Auke Bay in the same year with different sampling methods (Coyle \& Paul 1988). Differences between years in density of stage 1 zoeae may be attributable to the standing stock of ovigerous crabs, the number of eggs per female and to survival of embryos through development to hatching. Interannual variability in zoeal density of Dungeness crabs, Cancer magister was similar to that we measured for king crab larvae, with a 5-fold variation in maximum Dungeness crab zoeal density measured over a 5 yr period (Reilly 1983).

Primiparous crabs, females in their first reproductive season, have smaller carapace sizes and, in the laboratory, release larvae 2 to $3 \mathrm{wk}$ before the larger multiparous females (Shirley \& Shirley 1988b, M. Carls pers. comm.). A bimodal peak in the density of stage 1 zoeae in 1986 was evidence of 2 distinct hatching periods and may indicate the presence of a substantial number of primiparous crabs in the population. The density of stage 1 zoeae was greatest in 1987, possibly indicating synchronized hatching of a predominantly multiparous population of female crabs. The density of stage 1 
zoeae was low in 1988 with the early hatching larvae presumably released from primiparous crabs.

The bimodal density curve of stage 1 red king crab zoeae was not unlike the larval density curves of crustaceans in which portions of the populations spawn biennially rather than annually (Andersson 1962), but red king crabs are annual spawners. Laboratory culture of over 150 ovigerous king crabs at ambient and experimental temperatures has provided convincing evidence that unhatched eggs are not carried through a second winter (Shirley \& Shirley 1988b).

The time of larval release was influenced by the primiparous or multiparous condition of the female and by the water temperature during incubation of the eggs (Shirley et al. 1987, Shirley \& Shirley 1988b). Ovigerous crabs incubated in the laboratory at different temperatures from the time of egg deposition to hatching exhibited incubation periods that were inversely related to incubation temperature (Nakanishi 1987, Shirley et al. 1987. Shirley \& Shirley 1988b). Hatching in Dungeness crabs also occurred earlier in years with warmer water temperatures compared to years with colder water temperatures (Reilly 1983). Although bottom water temperatures in Auke Bay were not measured throughout the entire annual incubation period, warmer water temperatures in the late winter and spring of 1987 and 1988 corresponded to earlier appearances of king crab zoeae in the plankton.

Water temperature also affects length of the planktonic larval period by influencing the length of larval intermolt periods (Kurata 1960, Nakanishi 1987). The bimodal release of larvae from primiparous and multiparous females lengthens the total larval period because stage 1 zoeae are present in the water column longer. In 1985 and 1987, hatching occurred within a short interval, and the length of larval periods in those years may have been influenced primarily by colder water temperatures. Water temperatures were warmer in 1988 than in 1986 and should have resulted in a shorter larval period, but 3 maxima of hatching were evident in 1988 resulting in a prolonged period of larval release.

Estimated mortality and survival of king crab larvae varied between years from 1985 to 1988; survival to glaucothoe ranged from 0.7 to $3.0 \%$ and survival from zoeal stages 1 to 4 ranged from 12.6 to $14.9 \%$. Previous estimates of survival of king crab zoeae from egg to first benthic instar crab were less than $2 \%$ (Marukawa 1933, Bright 1967, Fukuhara 1985). Mortality for 1987 and 1988 could be slightly higher than reported because low densities $\left(<1.0100 \mathrm{~m}^{-3}\right)$ of stage 1 zoeae were present in the plankton before sampling began and were not included in mortality calculations from stage 1 to stage 2 .

Mortality estimates from instar analysis are based on the assumptions that development is isochronal and that immigration of larvae into the study area is equal to emigration. In laboratory studies, the intermolt period for zoeal stages 1 through 3 was isochronal and was ca $14 \mathrm{~d}$ at $6^{\circ} \mathrm{C}$ (pers. obs.). Emigration and immigration of king crab larvae in Auke Bay may be unimportant as suggested by the following evidence. Concurrent zooplankton sampling at lower intensity (one sample per station per week) during our study period found similar densities of king crab larvae inside and outside of the bay, while larval densities at different stations within the bay were also similar except after exchanges of water between the bay and outside waters caused by infrequent, sustained high winds (Coyle \& Paul 1988). Decreases in the density of king crab larvae at our sampling station throughout the study period were not correlated with the occurrences of such wind events. The settlement of glaucothoe in areas near our sampling area and the occurrence of first-instar and early juvenile crabs in intertidal habitats in Auke Bay (Molyneaux \& Shirley 1988) also suggest that there is little movement of larvae away from the spawning area.

Mortality estimates calculated from instar analysis do not distinguish loss of larvae to settling or predation from loss due to starvation. A decrease in density between stage 4 zoeae and glaucothoe is expected due to settling of glaucothoe out of the water column. However, glaucothoe initially undergo a pattern of diel vertical migration as do other king crab larval stages (Shirley \& Shirley 1987). The length of time between the molt to glaucothoe and permanent settlement to the benthos is not known for red king crabs. Calculation of survival to stage 4 zoeae instead of to glaucothoe eliminates the uncertainty of loss of settling larvae. Nonetheless, the first 2 zoeal stages are the critical stages for survival of king crab larvae in relation to their timing with the spring phytoplankton bloom. Stages 1 and 2 are primarily herbivorous stages that would theoretically derive the greatest benefit from synchrony with the bloom.

Sources of mortality other than starvation are potentially very important but are not addressed in this study. Predation is difficult to estimate in the field, but may be a major contributor to larval mortality. The estimated mortality between larval stages may be due partly to predation, but natural mortality occurs as larvae molt from one stage to the next. In the absence of predators, up to $50 \%$ of stage 1 zoeae may die in the laboratory while attempting to molt (pers. obs.). Molting mortality may contribute greatly to the total mortality of king crab larvae.

Although considerable variation was measured in hatching time and length of larval period, the timing of the spring phytoplankton bloom was remarkably con- 
sistent from 1985 to 1988 . The maximum chlorophyll concentrations occurred within an $11 \mathrm{~d}$ period from 29 April to 5 May over 4 yr. Chlorophyll abundance varied somewhat between years, but phytoplankton species composition was similar in all years except 1988 when the majority of diatoms in the bloom were Thalassiosira (Sato 1986, Ziemann 1986, Ziemann et al. 1987. Ziemann et al. 1988, Ziemann pers. comm.).

The success or failure of Calanus finmarchicus nauplii is related to brood timing with spring diatom blooms (Marshall et al. 1934). In contrast, survival of king crab larvae was related neither to temporal synchrony with the spring phytoplankton bloom nor to chlorophyll concentrations during the bloom. In 1985 and 1987, maximum densities of stage 1 zoeae coincided with the spring bloom. In 1986, the year of lowest larval survival, only the first hatching zoeae were synchronized with the bloom, while most stage 1 zoeae were present after the bloom. In 1988, only the last hatching zoeae coincided with the bloom, but larval survival was the highest of all $4 \mathrm{yr}$. Prey field abundance in Auke Bay may have been higher than the minimum required for survival by red king crab zoeae (A. J. Paul pers. comm.).

The substantial degree of interannual variability in the density, timing and survival of larval red king crabs and in hydrographic variables make predictions of recruitment unreliable. In a 6 yr study of Dungeness crabs in California, no relationship was established between larval abundance and subsequent recruitment of adult crabs to the commercial fishery (Reilly 1983). The potential use of larval population attributes for long range predictions of recruitment success of red king crabs will require additional quantitative measurements of juvenile and/or adult crab densities for correlation with the larval plankton data.

Acknowledgements. We thank L. Haldorson, J. Watts, D Sterritt and M. Pritchett for field callection of samples, A. Arra for quantifying plankton, D. Erickson for technical assistance, $M$. Carls of NMFS for providing laboratory hatching data, and members of the Oceanic Institute for collection of hydrographic and phytoplankton data. Funding for this research was provided by the National Oceanic and Atmospheric Administration contract NA-85-ABH-022 as part of APPRISE.

\section{LITERATURE CITED}

Allen, M. B. (1971). High latitude phytoplankton. Ann. Rev. Ecol. Syst. 2: 261-276

Andersson, F. S. (1962). The Norway lobster in Faeroe waters. Meddr. Danm. Fisk. -og. Havunders., N. S. 3: 265-325

Blau, S. F. (1986). Recent declines of red king crab Paralithodes camtschatica populations and reproductive conditions around the Kodiak Archipelago, Alaska. In: Jamieson, G. S., Bourne, N. (ed.) North Pacific workshop on stock assessment and management of invertebrates. Can. Spec. Publ. Fish. Aquat. Sci. 92: 360-369
Bright, D. B. (1967). Life histories of the king crab, Paralithodes camtschatica, and the 'tanner' crab, Chionoecetes bairdi, in Cook Inlet, Alaska. Ph. D. dissertation, University of Southern California.

Coyle, K. O., Paul, A. J. (1988). Zooplankton population and biomass in Auke Bay during the spring diatom bloom 1985-1987. In: APPRISE Annual Report, SFOS APP87-100, Vol. I. School of Fisheries and Ocean Sciences, University of Alaska Fairbanks, p. 195-253

Cushing. D. H. (1975). Marine ecology and fisheries. Cambridge University Press, Cambridge

Fukuhara, F. M. (1985). Biology and fishery of southeastern Bering Sea red king crab (Paralithodes camtschatica Tilesius). NOAA NWAFC Processed Rept. 85-11

Goering, J. C., Patton, C. J., Shiels, W. E. (1973a). Nutrient cycles. In: Hood, D. W., Shiels, W. E., Kelley, E. J. (eds.) Environmental studies of Port Valdez Univ. Alaska, Fairbanks. Inst. Mar. Sci. Occ. Publ. No. 3, p. 224-248

Goering, J. C., Shiels, W. E., Patton, C. J. (1973b). Primary production. In: Hood, D. W., Shiels, W. E. , Kelley, E. J. (eds.) Environmental studies of Port Valdez, Univ. Alaska, Fairbanks. Inst. Mar. Sci. Occ. Publ. No 3, p. 253-271

Haynes, E. B. (1974). Distribution and relative abundances of larvae of king crab, Paralithodes camtschatica, in the southeastern Bering Sea, 1969-70. Fish. Bull. U.S. 72: 804-812

Hewitt, R. P., Theilacker, G. H., LO, N. C. H. (1985). Causes of mortality in young jack mackerel. Mar. Ecol. Prog. Ser. 26: $1-10$

Incze, L. S., Otto, R. S., McDowell, M. K. (1986). Recruitment variability of juvenile red king crab, paralithodes camtschatica, in the southeastern Bering Sea. Can. Spec. Publ. Fish. Aquat. Sci. 92: 370-378.

Krebs, C. J. (1985). Ecology: the experimental analysis of distribution and abundance. Harper and Row, New York

Kurata, H. (1959). Studies on the larva and post-larva of Paralithodes camtschatica I. Rearing of the larvae, with special reference to the food of the zoea. Bull. Hokkaido reg. Fish. Res. Lab, 20: 76-83

Kurata, H. (1960). Studies on the larva and post-larva of Paralithodes camtschatica II. Feeding habits of the zoea. Bull. Hokkaido Reg. Fish. Res. Lab. 21: 1-8

Laws, E. A., Bienfang, P. K., Ziemann, D. A., Conquest, L. D. (1988). Phytoplankton population dynamics and the fate of production during the spring bloom in Auke Bay, Alaska. Limnol. Oceanogr. 33: 57-65

Marshall, S. M., Nicholls, A. G., Orr, A. P. (1934). On the biology of Calanus finmarchicus. V Seasonal distribution, size, weight and chemical composition in Loch Striven in 1933, and their relation to the phytoplankton J. mar. biol. Ass. U.K. 19: 793-823

Marukawa, H. (1933). Biological and fishery research on Japanese king crab Paralithodes camtschatica (Tilesius). J. imp. Fish. Exp. Stn, Tokyo 4 (37): 1-152

McMurray, G., Vogel, A. H., Fishman, P. A., Armstrong, D. A., Jewett, S. C. (1984). Distribution of larval and juvenile red king crabs (Paralithodes camtschatica) in Bristol Bay. U.S. Dep. Comer., NOAA, OCSEAP Final Rep. 53 (1986): $267-477$

Molyneaux, D. B, Shirley, T. C. (1988). Molting and growth of eyestalk-ablated juvenile red king crabs, Paralithodes camtschatica (Crustacea: Lithodidae). Comp. Biochem. Physiol. 91A: 245-251

Nakanishi, T. (1987). Rearing condition of eggs, larvae and post-larvae of king crab. Bull. Jpn Sea Reg. Fish. Res. Lab. $37 \cdot 57-161$

Nakanishi, T., Naryu, M. (1981). Some aspects of large-scale 
rearing of larvae and post-larvae of the king crab (Paralithodes camtschatica). Bull. Japan. Sea reg. Fish. Res. Lab. 32: $39-47$

Otto, R. S. (1986). Management and assessment of eastern Bering Sea king crab stocks. In: Jamieson, G. S., Bourne, N. (eds.) North Pacific workshop on stock assessment and management of invertebrates. Can. Spec. Publ. Fish. Aquat. Sci. 92: 83-106

Paul, A. J., Coyle, K. O. (1986). Grazing and predation by king crab larvae. Summary of 1985 A.PPRISE Research Program, Report to NOAA, p. 373-387

Paul, A. J., Paul, J. M. (1980). The effect of early starvation on later feeding success of king crab zoeae. J. exp. Mar Biol. Ecol. 44: 247-251

Reilly, P. N. (1983). Dynamics of dungeness crab, Cancer magister, larvae off central and northern California. In: Wild, P. W., Tasto, R. N. (eds.) Life history, environment, and mariculture studies of the Dungeness crab. Cancer magister, with emphasis on the central California fishery resource. Calif. Dep. Fish Game Fish Bull. 172: 57-84

Rigler, F. H., Cooley, J. M. (1974). The use of field data to derive population statistics of multivoltine copepods. Limnol. Oceanogr. 19: 636-655

Sato, S., Tanaka, S. (1949a). Study on the larval stage of paralithodes camtschatica (Tilesius) I. Morphological research. Scient. Rep. Hokkaido Fish. expl Stn (Hokkaido Suisan Shikenjo, Hokusuishi) 1: 7-24

Sato, S., Tanaka, S. (1949b). Study on the larval stage of Paralithodes camtschatica (Tilesius), II. On the rearing Scient. Rep. Hokkaido Fish, expl Stn 3: 18-30

Sato, V T (1986). Phytoplankton succession and sedimentation in Auke Bay, Alaska, during the 1985 spring bloom. In: APPRISE Annual Report, UAJ SFS-8603. School of

This article was submitted to the editor
Fisheries and Sciences, University of Alaska Juneau, p. 292-387

Shirley, S. M., Shirley, T. C. (1988a). Behavior of red king crab larvae: phototaxis, geotaxis and rheotaxis. Mar, behav. Physiol. 13: 369-388

Shirley, S. M., Shirley, T C., Rice, S. D. (1987). Latitudinal variation in Dungeness crab zoeal morphology explained by incubation temperature. Mar. Biol. 95 (3): 371-376

Shirley, T. C., Shirley, S. M. (1987). Diel vertical movements of Alaskan red king crab zoeae. Am. Zool. 27 (4): 103 A

Shirley, T C., Shirley, S. M. (1988b). Variables affecting hatching time of Alaskan red king crab. Am. Zool. 28 (4): 63 A

Townsend, D. W. Cammen, L. M. (1988). Potential importance of the timing of spring phytoplankton blooms to benthic-pelagic coupling and recruitment of juvenile demersal fishes. Biol. Oceanogr. 5: 215-229

Ziemann, D. A. (1986). Patterns of oceanographic conditions and particulate sedimentation in Auke Bay, Alaska, during the spring bloom, 1985. In: APPRISE Annual Report, UAJ SFS-9603. School of Fisheries and Sciences, University of Alaska Juneau, p. 143-244

Ziemann, D. A., Conquest, L. D., Bienfang, P. K., Antill, E (1987). Patterns of primary production and sedimentation during the 1986 spring bloom in Auke Bay, Alaska. In: APPRISE Annual Report Data Appendices, Vol. II, SFOS APP 87-100. School of Fisheries and Ocean Sciences, University of Alaska Fairbanks, p. 1-310

Ziemann, D. A., Conquest, L. D., Bienfang, P. K., Kanda, J. (1988). Patterns of primary production and sedimentation during the 1987 spring bloom in Auke Bay, Alaska. In APPRISE Annual Report, Vol. I, SFOS APP 87-100. School of Fisheries and Ocean Sciences, University of Alaska Fairbanks, p. 29-194

Manuscript first received: October 7, 1988

Revised version accepted: February 17, 1989 